\title{
Hypothalamic-pituitary-adrenal and cardiac autonomic responses to transrectal examination differ with behavioral reactivity in dairy cows
}

\author{
L. Kovács, ${ }^{\star} \dagger^{1}$ F. L. Kézér, ${ }^{*} \dagger$ M. Kulcsár-Huszenicza,† F. Ruff,§ O. Szenci,† and V. Jurkovich\# \\ ${ }^{*}$ MTA-SZIE Large Animal Clinical Research Group, Üllö-Dóra major 2225, Hungary \\ †Institute of Animal Husbandry, Faculty of Agricultural and Environmental Science, Szent István University, Páter Károly utca 1, Gödöllő 2100 , \\ Hungary \\ ‡Department and Clinics of Reproduction, Faculty of Veterinary Science, Szent István University, István utca 2, Budapest 1078, Hungary \\ §Department of Methodology, Hungarian Central Statistical Office, Budapest, Keleti Károly utca 5-7. H-1024, Hungary \\ \#Department of Animal Hygiene, Herd Health and Veterinary Ethology, Faculty of Veterinary Science, Szent István University, István utca 2, \\ Budapest 1078, Hungary
}

\section{ABSTRACT}

Behavior, hypothalamic-pituitary-adrenal axis, and cardiac autonomic nervous system (ANS) activity were evaluated in response to transrectal examination in nonlactating Holstein-Friesian cows with different behavioral reactivity. According to behavioral reactions shown to the procedure of fixing the heart rate (HR) monitors, the 20 cows with the highest and the 20 cows with the lowest behavioral reactivity were involved in the study (high responder, $\mathrm{n}=20$; and low responder, $\mathrm{n}=20$, respectively). Activity of the ANS was assessed by $\mathrm{HR}$ and $\mathrm{HR}$ variability parameters. Blood and saliva were collected at 5 min before (baseline) and 0, 5 10, $15,20,30,40,60$, and $120 \mathrm{~min}$ after the examination to determine cortisol concentrations. The examination lasted for $5 \mathrm{~min}$. Cardiac parameters included HR, the root mean square of successive differences between the consecutive interbeat intervals, the high frequency (HF) component of heart rate variability, and the ratio between the low frequency (LF) and HF parameter (LF/ $\mathrm{HF}$ ). Following the examination, peak plasma and saliva cortisol levels and the amplitude of the plasma and saliva cortisol response were higher in high responder cows than in low responders. Areas under the plasma and saliva cortisol response curves were greater in high responder cows. Plasma and salivary cortisol levels correlated significantly at baseline $(\mathrm{r}=0.91)$, right after examination $(\mathrm{r}=0.98)$, and at peak levels $(\mathrm{r}=0.96)$. Area under the HR response curve was higher in low responder cows; however, maximum $\mathrm{HR}$ and the amplitude of the HR response showed no differences between groups. Minimum values of both parameters calculated for the examination were higher in high responders. Following the examination, response parameters of root mean square of successive differences and HF did

Received September 28, 2015.

Accepted May 31, 2016.

${ }^{1}$ Corresponding author: Kovacs.Levente@mkk.szie.hu not differ between groups. The maximum and the amplitude of $\mathrm{LF} / \mathrm{HF}$ response and area under the LF/ $\mathrm{HF}$ response curve were lower in low responder cows, suggesting a lower sympathetic activation of the ANS. Although changes in behaviors indicated that the procedure was painful for the animals, no differences were observed either in vocalization or in attendant behavior between groups during the examination. Our results demonstrate that behaviorally more reactive animals exhibit increased plasma and salivary cortisol concentrations and higher cardiac autonomic responsiveness to transrectal examination than less reactive cows. Salivary cortisol may substitute for plasma cortisol when assessing response of cattle to stress.

Key words: behavioral reactivity, plasma cortisol, saliva cortisol, heart rate variability, dairy cattle

\section{INTRODUCTION}

Transrectal examination of the uterus (i.e., palpation of the reproductive tract via the rectum wall) in cattle became a routine procedure in commercial dairy herds for diagnosing early pregnancy and identifying cows at risk of postpartum infections (LeBlanc et al., 2002; Romano et al., 2007). It is performed multiple times during lactation, and despite being nontraumatic, it might be painful for the animals as reflected by plasma cortisol concentrations (Cingi et al., 2012). As acute stress during rectal palpation reduce conception rate (Unshelm, 1990), the effect of transrectal examination on bovine stress reactions has been evaluated in relation to positive human contact (Waiblinger et al., 2004) or the estrus cycle (Nakao et al., 1994). Response to pain as a form of acute stress includes a cascade of neurohormonal and behavioral (fight or flight) events (Molony and Kent, 1997; Mellor et al., 2000). Therefore, physiological and behavioral measures are often combined in pain assessment in farm animals (Prunier et al., 2013). Acute responses to noxious stimuli include activation of the hypothalamic-pituitary-adrenal (HPA) axis and 
the autonomic nervous system (ANS). Acute pain activates the sympathetic nervous system (SNS) to release catecholamines from the adrenal medulla. The HPA stress-response system reacts longer term; however, the early phase of this activation is difficult to measure (Mormède et al., 2007). Pain biomarkers related to the HPA axis are often measured in biological samples (e.g., blood). Plasma cortisol concentrations have been widely used to evaluate HPA axis activity in painful procedures in calves (Stafford and Mellor, 2011) and in adult cattle (Lay et al., 1992; Fidan et al., 2010). According to human studies, psychobiological mechanisms, which trigger the HPA axis, can be assessed by salivary cortisol concentrations (Hellhammer et al., 2009; Kudielka et al., 2009) that reflect unbound (i.e., free) cortisol (Kirschbaum, 2000; Möstl and Palme, 2002). In farm animal studies, saliva samples can be easily taken at fixed time intervals before and after an imposed stress (Mormède et al., 2007), and it is considered to be a minimally invasive method for the assessment of cortisol reactivity (Cook, 2012).

Several authors found a direct relationship between cortisol concentrations in saliva and plasma in pigs (Cook et al., 1996), dogs (Vincent and Michell, 1992), and sheep (Fell et al., 1985), whereas others observed that the correlation is limited (Blackshaw and Blackshaw, 1989; Bohák et al., 2013). The small number of studies on dairy cattle have shown that salivary and plasma cortisol correlate relatively well (Negrao et al., 2004; Hernandez et al., 2014).

Because extensive connections exist between the neural structures involved in pain sensation and autonomic function (Benarroch, 2006), heart rate (HR) has been studied parallel to HPA measures to describe the possible associations between painful stimuli and cardiac autonomic activity in animals (Haga and Ranheim, 2005; Stewart et al., 2008). The increase in HR results from reduced parasympathetic nervous system (PNS) activity or increased SNS activity or, in most cases, from a combination of concurrent changes within both branches (von Borell et al., 2007). Therefore, when assessing cardiac autonomic reactivity, it is difficult to draw exact conclusions based on solely the HR. Heart rate variability (HRV) attempts to distinguish the relative contributions of the SNS and the PNS activity underlying the autonomic reactivity (Thayer et al., 2012).

In human medicine, it has been recognized that experimentally induced pain has a notable effect on HRV (Koenig et al., 2014). Heart rate variability has been studied increasingly in animal and veterinary research to investigate the autonomic regulation of the cardiac function (von Borell et al., 2007); however, there are only a few studies on the HRV response to pain in adult farm animals (horse: Rietmann et al., 2004; sheep: Stubsjøen et al., 2009). As variations in successive cardiac cycles are predominantly controlled by the nervus vagus (Porges, 2003), PNS-related parameters of HRV are often used in welfare studies on dairy cattle (reviewed by Kovács et al., 2014a). Time domain measures of HRV, especially the root mean square of successive differences (RMSSD) between the consecutive interbeat intervals (IBI) and the high frequency (HF) component of HRV was found to be strongly associated with PNS tone in dairy cattle (Kovács et al., 2014a). The low frequency (LF) component of HRV is influenced by the baroreceptor modulation of both branches of the ANS (Rahman et al., 2011), whereas the relative power of the low and high frequency bands ( $\mathbf{L F} / \mathbf{H F})$ is believed to reflect the sympathovagal balance (van Ravenswaaij-Arts et al., 1993). Changes in PNS activity and sympathovagal balance as possible indicators of pain were reported in dairy calves exposed to routine husbandry procedures (Stewart et al., 2008, 2010) and in dairy cows during unassisted calving (Kovács et al., 2015c). Occurrence and extent of different behavioral reactions have been also used to assess pain (Marti et al., 2010; Pilz et al., 2012); however, it is limited by the subjective interpretations of different observers and that individuals show different behaviors to a similar stimulus (Livingston, 2010). As recent studies demonstrated individual characteristics in behavioral (Koolhaas et al., 2010), cardiac (Kovács et al., 2015b), and HPA axis reactivity (Curley et al., 2008), it seems necessary to consider behavioral traits in physiological studies. Specific endophenotypes have also been described in laboratory animal species on the basis of endocrine parameters (Sgoifo et al., 1996), cardiac blood pressure (Fokkema et al., 1988), or HR and HRV (Fenzl et al., 2011). Only a few studies on farm animals are available. Low PNS and high SNS activity were connected to higher emotional reactivity in horses (Visser et al., 2002), and it is possible that HRV and temperament are associated also in cattle (Frondelius et al., 2015; Kovács et al., 2015b). The HPA axis activity can be typified on the basis of behavioral traits in a stressful holding pen situation (Curley et al., 2008) or in an ACTH challenge and parlor milking (Negrao et al., 2004). Elevated cortisol concentrations have been observed in cattle that are more reactive to humans when compared with calmer animals (Fell et al., 1999; Curley et al., 2006). So far, no information is available regarding the parallel evaluation of HPA and ANS reactivity of dairy cattle of differing personality characteristics.

On the basis of previous findings (Kovács et al., $2014 \mathrm{~b}$ ), the present study was aimed to expand the knowledge on differences in pain-related behaviors, plasma and salivary cortisol concentrations, HR and 
HRV of dairy cows related to behavioral characters before, during, and following transrectal examination. As the rectum is considered as a visceral organ and has only autonomic innervations, it was expected that, complementary to HPA and behavioral measures, the assessment of cardiac autonomic function would be useful to evaluate the reactions of cows to the procedure. In relation to plasma cortisol concentrations, the biological significance of salivary cortisol as a measure of pain was also tested.

\section{MATERIALS AND METHODS}

\section{Animals and Experimental Procedure}

The experiment was carried out in November 2013 during a 4-d period under normal weather conditions (mean $\pm \mathrm{SD}$; temperature: $8.4 \pm 2.3^{\circ} \mathrm{C}$ ) on a dairy farm housing 2,300 Holstein-Friesian cows (Bóly Ltd.,

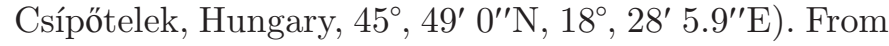
the 240 nonlactating, pregnant cows, kept in one group, 60 clinically healthy multiparous cows were selected for the study (means $\pm \mathrm{SD}$; age $=4.6 \pm 0.4 \mathrm{yr}$; parity $=$ $2.5 \pm 0.2$ lactation; day of gestation $=238 \pm 5 ; \mathrm{BCS}=$ $3.1 \pm 0.2$ ). Forty cows were involved in HPA and HRV measurements, based on the results of behavioral reactivity tests (see Behavioral Observations section). Cows had not been haltered, confined, or utilized in other research before this experiment. Animals were housed in freestall barns bedded with sand. They were fed a TMR once a day at $0900 \mathrm{~h}$, and water was available at all times. Each animal had prior experience undergoing rectal examination and each animal was palpated only once in the experiment.

The barns were equipped with self-locking headgates along the feeding area, which were used to restrain cows for regular veterinary checkups and necessary treatments, for a maximum of $2 \mathrm{~h}$. The experimental period was fit in the routine management schedule, which ensured that the animals were accustomed to the restraint and could be easily identified without moving or separating them. Heart rate monitors were fitted to the cows after feeding, while still restrained in self-locking headgates, $18 \mathrm{~h}$ before transrectal examinations (between 1600 and $1700 \mathrm{~h}$ ) to allow enough time to get used to wearing the equipment (Mohr et al., 2002; Gygax et al., 2008). The transrectal examination was performed the next day. Recordings started approximately $10 \mathrm{~min}$ after the animals had finished feed intake. The rectum was emptied, the mesenterial ligaments, arteria uterina media, cervix uteri, and pelvic bones were palpated for a duration of 5 min (Kovács et al., 2014b). It took place between 1045 and $1100 \mathrm{~h}$ on each experimental day to avoid any possible confounding effects of circadian and ultradian rhythms of the cortisol secretion (Lefcourt et al., 1993) and HRV (Kovács et al., 2016). Five experienced veterinarians participated in the experiment. Ten cows were involved per day in 2 successive sessions, each including five-five animals that were examined simultaneously, in 2 consecutive sessions. The recording of the IBI continued for 120 min following the examination. Blood and saliva samples for the assessment of cortisol concentrations were taken repeatedly in the 120 min following the transrectal examination. Any unnecessary contact with animals throughout the whole experimental period was avoided.

\section{Behavioral Observations}

Behavioral Reactivity. Data concerning the animals' behavioral responsiveness were recorded directly by 3 independent judges at the time of fixing the HR receivers based on a detailed and direct observation including (1) restlessness (Table 1), (2) stepping/kicking rate, and (3) frequency of defecation, urination, and vocalization. Fixing the HR monitors was necessary, and as a sudden, unfamiliar, and unpredictable event, we found it appropriate to evaluate the behavioral reactivity of the animals (Forkman et al., 2007). To determine inter-observer repeatability, we calculated Cohen's kappa coefficient with 4 categorical variables according to Table 1 (i.e., restlessness 1 to 4). Among veterinarians, Cohen's kappa was 0.72 .

In case of restlessness behavior, a mean score for each animal was calculated following the procedure. Stepping/kicking was calculated for frequency per minute and defined as described by Wenzel et al. (2003) and scored as follows: 1 (between 0 and 2), 2 (between 3 and 4), 3 (between 5 and 7), and 4 (higher than 7). Frequency of defecation, urination, and vocalization were also calculated for $1 / \mathrm{min}$ and since previous work has shown that they are highly correlated (De Passillé

Table 1. Categories of restlessness recorded during the fixing of the electrode belts

\begin{tabular}{lll}
\hline Description & Score \\
\hline Standing calm without any obvious reaction & 1 \\
Standing calm, tail flicking, infrequent muscle contractions, or a combination of these & 2 \\
Tail flicking, frequent muscle contractions, or both; head shaking & 3 & \\
Head shaking, defense reactions, or both (e.g., butting); or fall (the cow collapses to the ground onto both knees) & 4 \\
\hline
\end{tabular}


et al., 1995), they were normalized and calculated for frequency per minute and then scored the same way as stepping/kicking rate, with scores from 1 to 4 . An individual response score (IRS) was calculated for each animal, as follows: $0.5 \times$ restlessness behavior $+0.3 \times$ stepping/kicking rate $+0.2 \times$ defecation/urination/vocalization. From a total of 60 cows tested for behavioral reactivity, 20 with the highest scores (high responder group, IRS >2) and 20 with the lowest scores (low responder group, IRS $<1.4$ ) were chosen as subjects of the transrectal examination study. Medium responder cows $(1.4<$ IRS $<2)$ were not involved in further analysis.

Transrectal Examination. Because animals reacted less intensively to the examination than to fixing the electrodes, only vocalization and attendance were considered as signs of discomfort (Pilz et al., 2012). Attendant behavior was defined as the animal's attempts to turn the head toward the hind quarter during the examination. The occurrence and frequency of vocalizations and attendant behavior were observed by veterinarians who performed the palpation and by assistant persons, independently, during 3 different periods as follows: (1) baseline (i.e., the last 5 min before the first blood and saliva sampling), (2) examination, and (3) the first 5 min following the examination. Experimenters were continuously present in the cows' proximity during the examination and during blood collection, whereas assistants were present only during the saliva samplings, in front of the animals. Counts of the behavioral events registered by the 2 observers were then averaged and calculated for frequency per minute. The operators' effect (arising from the differences in arm circumferences between veterinarians) was taken into consideration as all investigators examined 4 low responder and 4 high responder cows.

\section{Plasma Cortisol}

Blood (approximately $7 \mathrm{~mL}$ ) was collected by venipuncture from the coccygeal vein immediately before saliva samples into heparinized tubes (S-Monovette, Sarstedt, Nümbrecht-Rommelsdorf, Germany). Baseline was determined as 5 min before the examination has started (time -1). Further samples were taken immediately after transrectal examination (time 0) and at 5, 10, 15, 20, 30, 40 60, and 120 min thereafter. The average duration of sampling was $10 \mathrm{~s}$. In general, cows stood calm during sampling. The blood samples were cooled to and stored at $4^{\circ} \mathrm{C}$ until centrifugation at 3,000 $\times g$ for $5 \mathrm{~min}$ at room temperature. The plasma was removed and frozen at $20^{\circ} \mathrm{C}$ until cortisol assay. A direct homemade RIA method was used, which was developed for cortisol determination in plasma of food animals us- ing 1,2,6,7-3H-cortisol (TRK 407; Radiochemical Centre, Amersham, UK) and a highly specific polyclonal antibody raised against cortisol-21-HS-BSA in rabbits (Csernus, 1982). Cross-reactivity of the assay: cortisol: 100\%; corticosterone: 19\%; prednisolon: $9.5 \%$; deoxycortisol: $6.4 \%$; $17 \alpha-\mathrm{OH}$ progesterone: $5.7 \%$; progesterone: $2.6 \%$; any other 22 steroids: 0.54 to $0.0001 \%$ ). The assay standards (cortisol FW 362.5; Sigma Chemical Company, St. Louis, MO) were prepared in cortisolfree plasma (range: 2,000 to $31.25 \mathrm{fmol}$ per tube). The antibody-bound and the free fractions were separated by cold dextran-coated charcoal suspension after an 18 to $24 \mathrm{~h}$ incubation period. Radioactivity was measured by a TriCarb liquid scintillation counter (Perkin Elmer Inc., Downers Grove, IL). The sensitivity of this assay system was $11.37 \mathrm{fmol} /$ tube. Within the concentration range of about 2.0 and $100.0 \mathrm{nmol} / \mathrm{mL}$ the intra- and interassay coefficients of variation varied between 3 and $8 \%$, as well as 5 and $10 \%$, respectively. Samples with cortisol concentration higher than $100.0 \mathrm{nmol} / \mathrm{L}$ had to be re-assayed after dilution (Csernus, 1982).

\section{Salivary Cortisol}

Using a synthetic swab (Salivette Cortisol, Sarstedt), each saliva sample was taken immediately following the blood sample. The swabs were placed loosely onto the tongue of the cow until it was well soaked with saliva. This procedure required up to $30 \mathrm{~s}$, which the animals tolerated without resistance. The swabs were then inserted into Salivette polypropylene tubes, which were placed on ice immediately after sampling and stored at $4^{\circ} \mathrm{C}$ until centrifugation at $1,000 \times g$ for $10 \mathrm{~min}$ at room temperature. At least $1.5 \mathrm{~mL}$ of saliva per sample was obtained and frozen at $-20^{\circ} \mathrm{C}$ until analysis. Cortisol was determined by a direct radioimmunoassay without extraction as described in the Plasma Cortisol section.

\section{$H R$ and HRV}

The IBI were recorded using a mobile recording system that included a Polar Equine $\mathrm{T} 56 \mathrm{H}$ transmitter with 2 integrated electrodes in a flexible belt, a compatible Polar H2 HR sensor, and a Polar RS800 CX HR monitor (POLAR, Kempele, Finland). Electrode sites were covered with ample ultrasound transmission gel (Aquaultra Blue, MedGel Medical, Barcelona, Spain). Transmitters and electrodes were positioned as advised by von Borell et al. (2007) and fitted to the animals with a leather girth. Devices were removed from the cows 30 min after the last blood and saliva collection was completed. 
The IBI data recorded from 5 min before the examination to $120 \mathrm{~min}$ afterward were used for analysis. The analysis was performed with the Kubios HRV software (version 2.2, Biomedical Signal Analysis Group, Department of Applied Physics, University of Kuopio, Finland; Tarvainen et al., 2014). For artifact correction, the custom filter was chosen and set at 0.3 , identifying IBI differing from the previous one by more than $30 \%$ as artifacts. After abnormal interval removal, the algorithm of the program substitutes the detected errors with interpolated IBI calculated from the differences between previous and next accepted IBI. Following this procedure, a visual inspection of the corrected data series was performed to edit out any artifacts still existing (generally Type 4 and Type 5 errors, which were described by Marchant-Forde et al., 2004 in detail). For removing slow nonstationary trend components, the smoothness priors-based detrending method was chosen with $\lambda=1,000$ and $\mathrm{f}_{\mathrm{c}}=0.029 \mathrm{~Hz}$.

Parameters in time- and frequency-domains were calculated as follows. In time domain, HR and RMSSD were quantified, which are used to estimate short-term beat-to-beat variations representing regulatory activity of the PNS and have been used for stress assessment in dairy cattle (Gygax et al., 2008; Kovács et al., 2013). In the frequency domain, IBI data were subjected to fast Fourier transformation (FFT) for power spectrum analysis (Akselrod et al., 1981). To account for interindividual differences in accordance with earlier studies (Mohr et al., 2002; Stewart et al., 2010), the LF and HF powers were presented in normalized units, and the LF/ HF was also calculated. The HF represents PNS tone, whereas LF/HF provides information on sympathovagal balance (ESC-NASPE Task Force, 1996). Limits of the spectral components were set as follows: LF: 0.05 to $0.20 \mathrm{~Hz}$, and HF: 0.20 to $0.58 \mathrm{~Hz}$ (for further details see reviews by von Borell et al., 2007, and Kovács et al., 2014a). Following recommendations of earlier reports on cattle (Mohr et al., 2002; Hagen et al., 2005) and to fulfill recommendations for analysis of IBI using FFT algorithm (ESC-NASPE Task Force, 1996) parameters of HRV were calculated for equal time windows of $5 \mathrm{~min}$. The HRV spectrum was calculated with the FFT-based Welch's periodogram approach with 256-s overlapping segments and $50 \%$ window overlap. The interpolation rate of $\mathrm{R}-\mathrm{R}$ data series was set to $4 \mathrm{~Hz}$. Baseline $\mathrm{HRV}$ variables were established during a 5 -min period immediately before the first saliva and blood sampling before examination representing an undisturbed period. Cardiac responses of the animals were than evaluated during the transrectal examination and in every 5-min time period immediately before each saliva and blood sample was taken thereafter.

\section{Statistical Evaluation}

All statistical analyses were performed in the R-3.0.2. statistical environment and language ( $\mathrm{R}$ Core Team, 2013). Data were tested for constant variance (Levene's test) and the Shapiro-Wilk test was used for testing the equality of error variances both in low and high responder groups. For the evaluation of HPA and cardiac autonomic responses separately in high responder and low responder groups, the repeated measures of ANOVA (in case of normal distribution of data) and the Friedman rank sum test were used (in case of nonnormality of data). Statistical significances were calculated between the concentrations in plasma and saliva cortisol, HR, RMSSD, HF, and LF/HF for the 10 time points of measurement. For this purpose, the Tukey's post-hoc test and the Neményi post-hoc test were used. Significance was set at $P<0.05$ for both tests, and all values are presented as the mean \pm 1 standard error of the mean for the figures.

To reduce the number of statistical comparisons between high responder and low responder groups during the postexamination period, cortisol and cardiac response parameters were calculated as area under the curve (AUC). The AUC represents both the magnitude and the changes over time of the response (Fekedulegn et al., 2007). Short-term response parameters included peak values of salivary and plasma cortisol concentrations, maximum HR, RMSSD, $\mathrm{HF}$ and $\mathrm{LF} / \mathrm{HF}$, and the amplitude (the maximal alteration compared with baseline) of the hormonal and cardiac responses. In case of PNS-related indices (RMSSD and HF), minimum values during the examination were also calculated. As a long-term measure of the physiological response reflecting on the magnitude of response, AUC were calculated for both HPA and cardiac measures. Areas under the response (RESP) curves were determined for the first 120 min following transrectal examination utilizing a trapezoid method described by Lay et al. (1996) as follows:

$$
\mathrm{AUC}_{\mathrm{RESP}}=\Sigma\left[\left(\mathrm{P}_{\mathrm{n}}+\mathrm{P}_{\mathrm{n}+1}\right) / 2 \times \mathrm{m}-\text { baseline }\right],
$$

where $\mathrm{P}$ is the response parameter at a given time point, $\mathrm{n}$ is the number of the time point, $\mathrm{m}$ is the time in minutes between the $2 \mathrm{P}$ values, and baseline is the mean value of recorded HR and HRV measures and of cortisol concentrations in plasma and saliva $5 \mathrm{~min}$ before the examination.

Comparisons between low responder and high responder groups for plasma and salivary cortisol as well as HR and HRV response parameters were made by paired $t$-test (in case of normal distribution of data) 
and by a Mann-Whitney U-test (in case of nonnormal distribution of data). Significance was set at the level of 0.05 in both cases.

Behavioral reactions during the examination and postexamination periods were quantified as changes in frequency compared with baseline (i.e., the last 5 min before the first blood and saliva sampling before transrectal examination). Then an ANOVA was used to compare differences between behavioral groups and a paired $t$-test was used to compare differences during examination and postexamination from baseline at the significance level of $P<0.05$. No vocalization was observed during the baseline and postexamination periods to enable statistical comparisons between periods within groups.

The relationship between plasma and saliva cortisol concentrations was evaluated by Bonferroni-corrected Pearson correlation coefficients. For this purpose, baseline, time 0 , and peak values were chosen involving both low and high responders in the analysis.

\section{RESULTS}

\section{Plasma and Salivary Cortisol}

Changes in plasma and saliva cortisol levels are presented in Figures 1(a) and 1(b). Before the examination, mean cortisol levels were below 2 and $0.2 \mathrm{nmol} / \mathrm{L}$ in low responder cows in plasma and in saliva, respectively, and below 3.5 and $0.4 \mathrm{nmol} / \mathrm{L}$ in high responder cows, with minor individual variations within groups.

Plasma cortisol concentrations increased after the examination had been finished in both groups compared with baseline levels (low responders: $P=0.002$, high responders: $P=0.007$ ) to reach their peak levels at $20 \mathrm{~min}$ in low responder cows and at $30 \mathrm{~min}$ in high responder cows $(P<0.001$ for both groups). Saliva cortisol showed a similar pattern with a sudden rise right after the examination (low responders: $P=0.001$, high responders: $P=0.010$ ) and with peak levels at 20 and at $30 \mathrm{~min}$ thereafter in low and high responders, respectively $(P<0.001$ for both groups). Afterward, a gradual decrease in cortisol concentrations was observed in both groups [Figures 1(a) and 1(b)].

In both specimens, cortisol concentrations decreased to the half of the peak levels $60 \mathrm{~min}$ after the examination was finished. Two hours postexamination, similar circulating cortisol concentrations were observed in both groups in both plasma and saliva, but concentrations were still significantly higher than basal levels (low responders: $P=0.034$ and $P=0.020$, high responders: $P=0.007$ and $P=0.011$, for plasma and saliva, respectively).

Baseline levels did not differ between groups in either plasma or saliva (Table 2). The peak levels and the a)

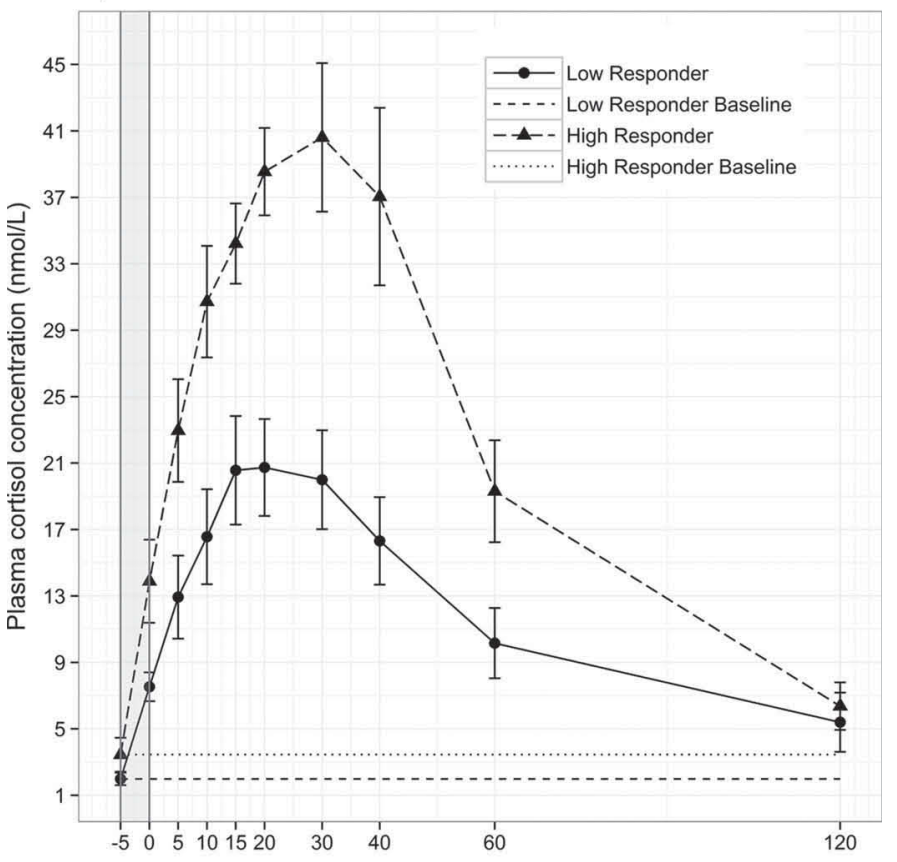

b)

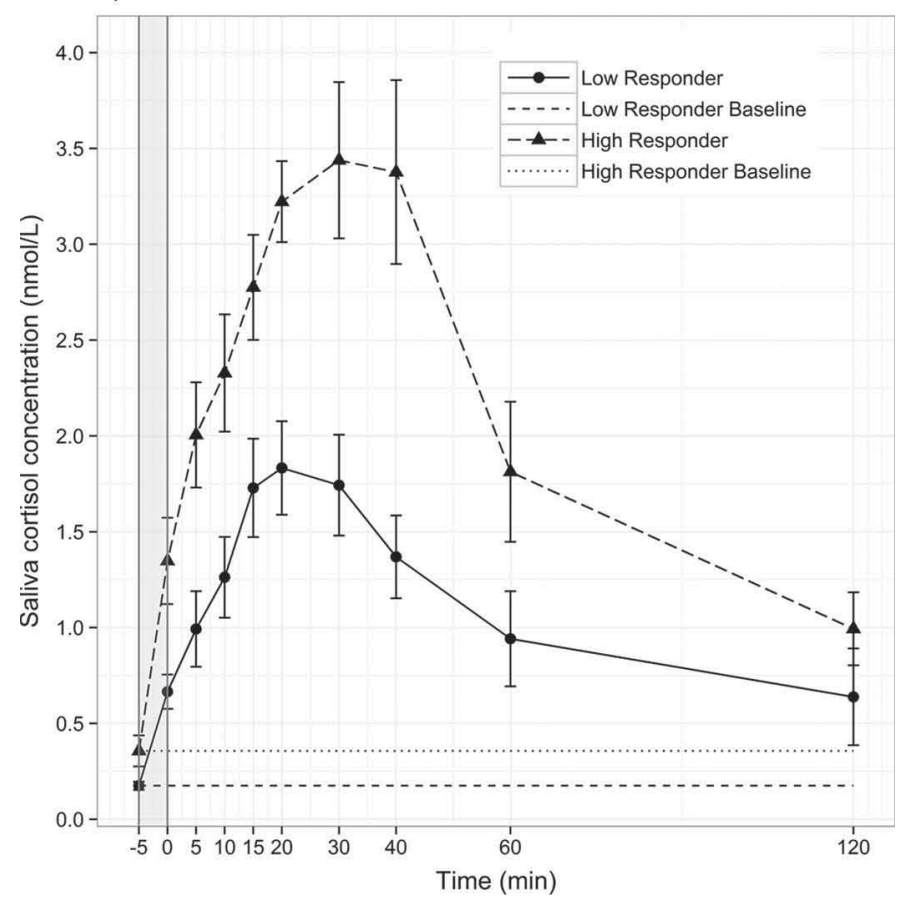

Figure 1. Cortisol concentrations in plasma (a) and in saliva (b) of low responder $(\boldsymbol{\Lambda}, \mathrm{n}=20)$ and high responder $(\boldsymbol{\bullet}, \mathrm{n}=20)$ cows before (time -5) and during a 120-min sampling period after transrectal examination. Data are given in means \pm SEM. The examination was performed between time -5 and time 0 (which represents the 5 -min examination).

amplitude of the cortisol response were higher in high responders than in low responders in both specimens. Cortisol release into plasma and saliva calculated as 
Table 2. Plasma and saliva cortisol concentrations calculated as area under the curve parameters of low responder $(\mathrm{n}=20)$ and high responder $(\mathrm{n}=20)$ cows in response to transrectal examination ${ }^{1}$

\begin{tabular}{|c|c|c|c|c|}
\hline Cortisol response parameter ${ }^{2}$ & Units & Low responder & High responder & $P$-value \\
\hline Baseline & $\mathrm{nmol} / \mathrm{L}$ & $1.9 \pm 1.2$ & $3.4 \pm 1.5$ & 0.230 \\
\hline Peak level & $\mathrm{nmol} / \mathrm{L}$ & $19.6 \pm 7.4$ & $40.8 \pm 14.8$ & 0.002 \\
\hline Amplitude of response & $\mathrm{nmol} / \mathrm{L}$ & $15.1 \pm 9.2$ & $37.7 \pm 16.6$ & 0.001 \\
\hline Area under the curve & $\mathrm{nmol} / \mathrm{L} \times \min$ & $1,213.9 \pm 527.7$ & $2,301.7 \pm 745.0$ & 0.020 \\
\hline Peak level & $\mathrm{nmol} / \mathrm{L}$ & $1.8 \pm 0.5$ & $3.5 \pm 0.8$ & 0.001 \\
\hline Amplitude of response & $\mathrm{nmol} / \mathrm{L}$ & $1.4 \pm 0.7$ & $3.2 \pm 1.1$ & 0.003 \\
\hline Area under the curve & $\mathrm{nmol} / \mathrm{L} \times \min$ & $110.1 \pm 48.2$ & $216.5 \pm 67.3$ & 0.037 \\
\hline
\end{tabular}

${ }^{1}$ Descriptive statistics are based on means \pm SD of nontransformed data.

${ }^{2}$ Baseline $=5$ min before the beginning of transrectal examination; amplitude of response $=$ the maximal alteration compared with baseline; area under the curve $=120$ min following transrectal examination. Statistical significances for baseline and response parameters of the hypothalamicpituitary-adrenal axis are based on results from the paired $t$-test and the Mann-Wilcoxon test.

AUC for the 120 min of the sampling period was also greater in high responder animals than in low responder ones (Table 2).

Although cortisol concentrations measured in plasma were substantially higher than that measured in saliva throughout the experimental period, the 2 profiles were similar in both groups. Plasma and salivary cortisol levels correlated significantly at baseline $(\mathrm{r}=0.91, \mathrm{n}$ $=40, P=0.001$ ), at time 0 (right after transrectal examination; $\mathrm{r}=0.98, \mathrm{n}=40, P=0.001)$ and at peak levels $(\mathrm{r}=0.96, \mathrm{n}=40, P=0.001)$.

\section{$H R$ and $H R V$}

Changes in HR and HRV parameters around the transrectal examination are shown in Figures 2(a) to $2(\mathrm{~d})$. Although high responder cows had in average 7.9 beats/min higher HR than low responders, the HR response showed a similar pattern in both groups [Figure 2(a)]. During the examination, HR suddenly increased ( $P<0.001$, in both groups), and then declined slowly to the baseline levels $120 \mathrm{~min}$ after the procedure was finished either in low $(P=0.351)$ and high responder animals $(P=0.307)$. Baseline HR was higher in high responder cows compared with low responders (Table $3)$. Area under the HR response curve was higher in low responder cows than in high responders. Maximum HR and the amplitude of the HR response showed no differences between groups (Table 3 ).

Changes in RMSSD and HF were similar in low and high responder cows throughout the measurement period [Figures 2(b) and 2(c)]. During transrectal examination, RMSSD drastically dropped in both low and high responder cows $(P=0.004$ and $P<0.001$ from baseline, respectively) reflecting a sudden decrease in PNS activity [Figure 2(b)]. In the first 5 min follow- ing the examination, RMSSD values increased highly above baseline in both groups $(P<0.001$ for both groups). The exact rate of the increase from minimum to maximum values was on average 79.4 and $122.3 \%$ in low responders and high responders, respectively. In both groups, 10 min after the examination RMSSD decreased again until min 20 and then gradually returned to the baseline levels 60 min after the procedure (low responders: $P=0.852$, high responders: $P=0.758$ ).

Similarly to RMSSD, HF rapidly decreased during the examination to the minimum values in both groups $(P<0.001)$ and reached the maximum values in the first $5 \mathrm{~min}$ following the procedure [Figure 2(c)]. The rate of the increase from minimum to maximum was on average 219.3 and $398.9 \%$ in low and high responder cows, respectively. The HF started to gradually increase 15 min after the examination in low responders and 20 min after the examination in high responders. Sixty minutes postexamination, HF showed no difference compared with baseline in both groups (low responders: $P=0.343$, high responders: $P=0.427$ ) and was slightly below the baseline levels 60 min following the examination, but these differences were nonsignificant.

Baseline values of RMSSD and HF did not differ between groups. Minimum values of both parameters calculated for the 5-min transrectal examination period were higher in high responder cows. Following the examination, the maximum and the amplitude of the RMSSD and HF response did not differ between groups, and although the area under the response curve was numerically different for both parameters, it was nonsignificant (Table 3).

Opposite to PNS parameters, LF/HF increased rapidly during the procedure in both high responders and low responders compared with baseline $(P<0.001$ for both groups), reflecting an increased SNS activity. In 
the first 5 min after the examination, LF/HF decreased drastically below baseline levels (Figure 2(d)] and from min 10 after the procedure finished until the end of

a)

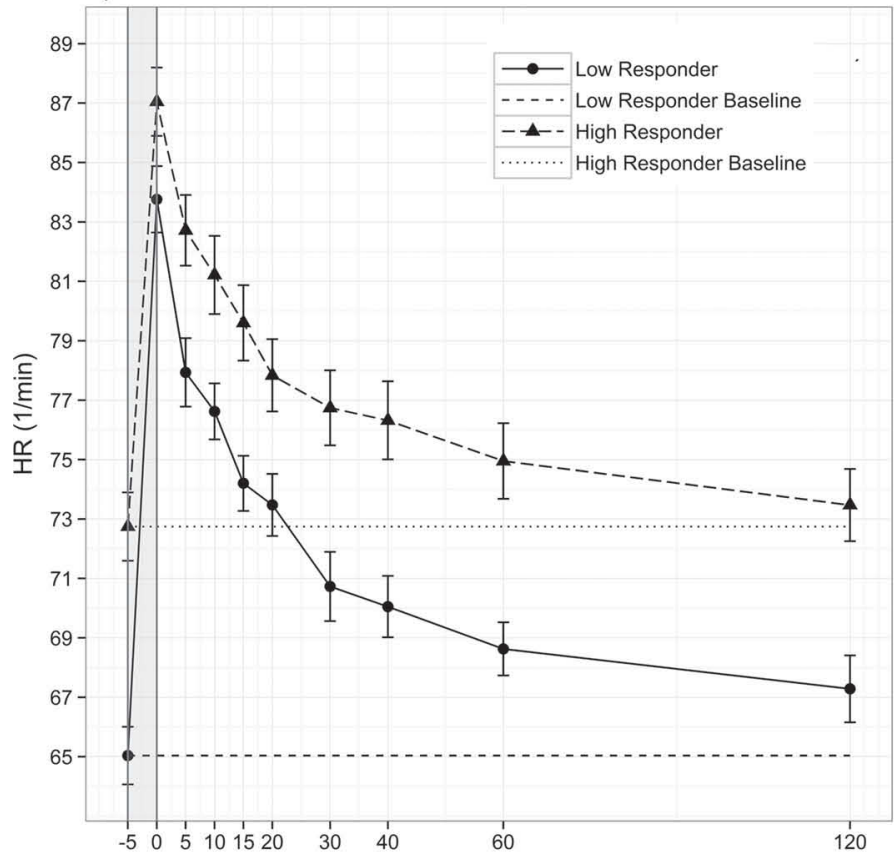

the recording period, it did not statistically differ from baseline (low responders: $P=0.552$, high responders: $P=0.307)$.

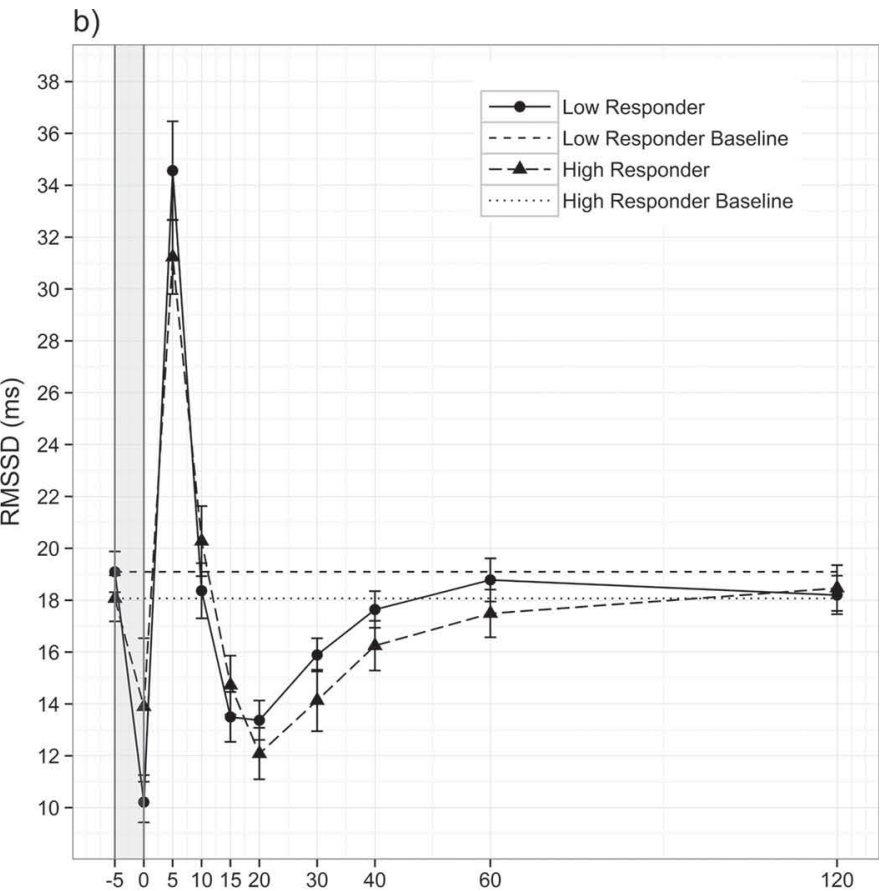

d)

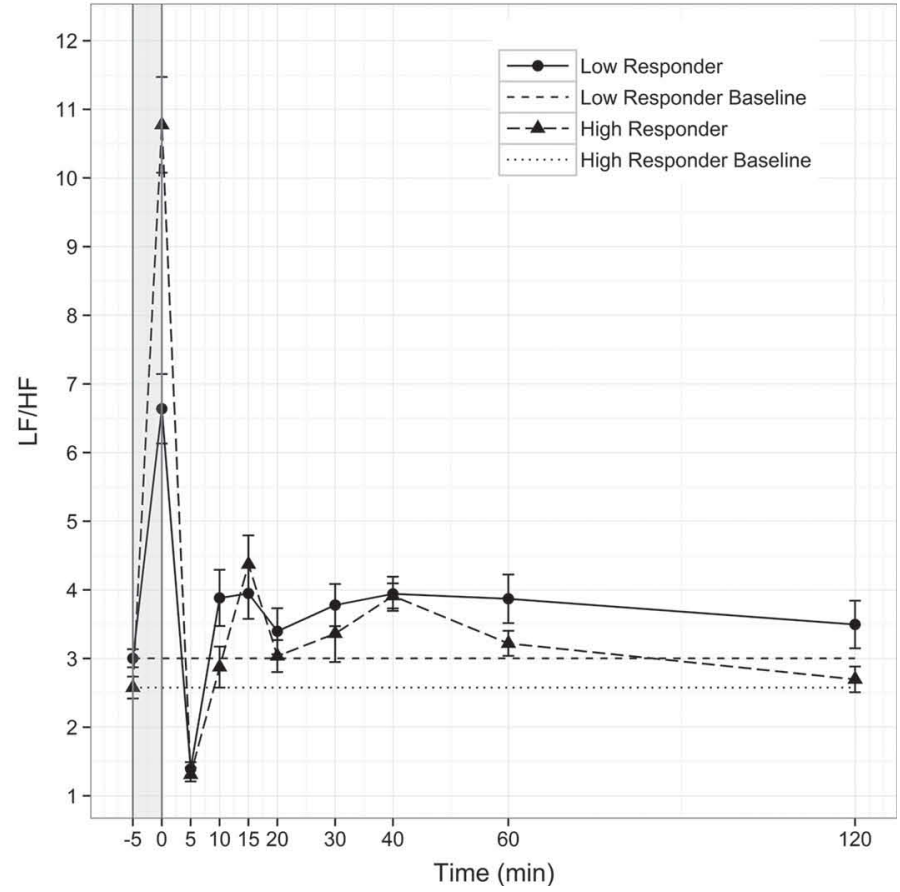

Figure 2. Heart rate (HR; a), the root mean square of successive differences (RMSSD) in interbeat intervals (b), the high frequency (HF) component of heart rate variability (c), and the ratio between the low frequency (LF) and the HF components (LF/HF; d) in low responder ( $\bullet$ $\mathrm{n}=20)$ and high responder $(\boldsymbol{\Lambda}, \mathrm{n}=20)$ cows before (time -5$)$, during and after transrectal examination. Data are given in means \pm SEM. Time -5 represents the last $5 \mathrm{~min}$ before the examination, time 0 represents the 5 -min examination, and time 5 represents the first 5 min following examination. n.u. = normalized unit. 
Although changes in LF/HF showed a similar pattern in low responder and high responder cows throughout the measurement period, except from baseline values, AUC analysis detected greater differences between groups. Maximum, amplitude of $\mathrm{LF} / \mathrm{HF}$, and area under the $\mathrm{LF} / \mathrm{HF}$ response curve were lower in low responder cows, suggesting lower SNS activation in low responders (Table 3 ).

\section{Behavior}

Vocalization occurred only during the examination in both groups (Table 4). During the examination, attendance behavior was $5.1 \pm 0.7(P=0.003)$ times and $4.8 \pm 1.3(P=0.008)$ times more frequent than baseline values in low responder and high responder cows, respectively. During the postexamination period, no attendant behavior was observed. There were no differences either in vocalization $\left(\mathrm{F}_{5,80}, P=0.780\right)$ or in attendant behaviors between groups $\left(\mathrm{F}_{5,160}, P=0.960\right)$ for any of the observed periods.

\section{DISCUSSION}

Recent investigations that focused on the associations between HR or HRV (or both) and individual characteristics such as temperament were generally designed without taking into account the effects of unfamiliar environments and restraint (Sutherland et al., 2012; Frondelius et al., 2015). In this study, transrectal examinations were fitted to the farm schedule and timed according to regular daily veterinary checkups. Characterization of cows' behavioral reactivity was done in the animals' familiar environment by a rapid test performed during the preparation procedure (i.e., fixing the electrocardiogram sensors on the animals) before the measurement period. It remains a question whether the composition of low and high responder groups would have changed if a recommended fear test (Forkman et al., 2007) had been applied; however, we tried to avoid any unnecessary contact with the cows to prevent adaptation to investigators or test situation.

The present findings demonstrate that transrectal examination induces significant elevation in HPA and cardiac autonomic activity in dairy cows, and that behaviorally more reactive animals showed greater physiological responses to the examination than relatively calmer ones. A distinct increase in cortisol concentrations was observed in both low and high responder cows in both plasma and saliva in response to the procedure. The rate of increase was substantially greater in plasma. In general, the present findings are similar to those

Table 3. Comparison of cardiac function [heart rate (HR), the root mean square of successive differences (RMSSD), high frequency (HF) component of heart rate variability and low frequency $(\mathrm{LF}) / \mathrm{HF}]$ calculated as area under the curve parameters of low responder $(\mathrm{n}=20)$ and high responder $(\mathrm{n}=20)$ cows in response to transrectal examination ${ }^{1}$

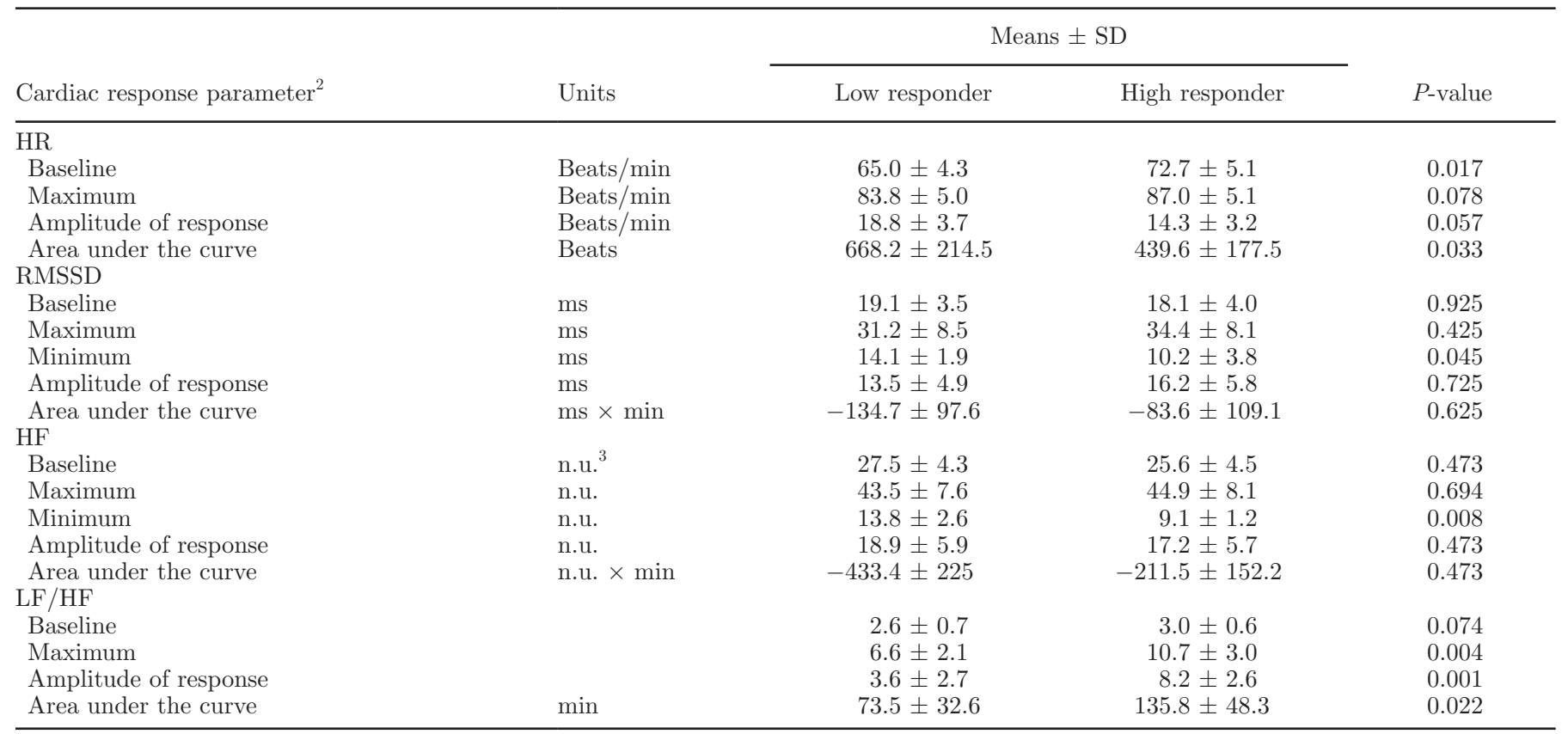

\footnotetext{
${ }^{1}$ Descriptive statistics are based on means $\pm \mathrm{SD}$ of nontransformed data.
}

${ }^{2}$ Baseline $=$ the last 5 min before the beginning of the transrectal examination; amplitude of response $=$ the maximal alteration compared with baseline; area under the curve $=120$ min following the transrectal examination.

${ }^{3}$ n.u. = normalized unit. 
observed in calves after ACTH administration (Veissier et al., 1999; Negrao et al., 2004) suggesting that transrectal examination means a high stress load for cows accompanied by pain. In their recent work, Cingi et al. (2012) found only a $25 \%$ increase in plasma cortisol concentrations after rectal examination. Although this increase seems to be minor compared with the 10-fold increments found for both low and high responder cows in this study, the comparison of the authors' results with the present study is difficult because the authors determined baseline levels $2 \mathrm{~h}$ before palpation and collected only one sample following the examination.

In low responder cows, the highest cortisol concentrations were observed at $20 \mathrm{~min}$ postexamination for plasma and saliva, whereas in high responders, cortisol levels peaked after $30 \mathrm{~min}$ in both matrices. The peaks in cortisol concentrations were not due to the sampling procedures because these levels were similar to those obtained after conventional milking (Rushen et al., 2001; Negrao et al., 2004). Two hours after the examination, similar circulating cortisol concentrations were observed in both groups for both plasma and saliva that were higher than basal concentrations. In the study of Nakao et al. (1994), plasma cortisol concentrations peaked $10 \mathrm{~min}$ following the examination, and the activation of the HPA axis persisted for only 25 min after the examination. It has to be noted that the animals involved were routinely used for practical education on bovine reproduction.

Pearson correlation coefficients indicated a highly significant positive relationship between the plasma and salivary cortisol concentrations calculated for baseline, postexamination, and peak levels. No time lag appeared between peaks of plasma and salivary cortisol. According to Hernandez et al. (2014), plasma cortisol positively correlated with saliva cortisol in dairy cows with a 10-min time lag $(\mathrm{r}=0.83)$. Negrao et al. (2004) also found a positive but weaker correlation between saliva and plasma cortisol concentrations $(\mathrm{r}=0.63)$. The authors explained their results with the fact that salivary cortisol reflects the free fraction, whereas plasma cortisol reflects both free and protein-bound fractions. The 3-min time lag between the saliva and blood samplings possibly influenced their results. Moreover, their restraint method and timing of samplings (in the phase of waiting after milking has finished) was potentially a source of stress for the animals (Kovács et al., 2013). In the present study, the examination and samplings were performed at the time and site of the daily veterinary checkups and treatments. Saliva sampling is a stressfree and effective method in cows that are habituated to human handling and to the experimental environment (Cook, 2012).

Baseline plasma and salivary cortisol concentrations did not differ between groups. Earlier observations found higher plasma (Fell et al., 1999; Curley et al., 2006, 2008) and serum cortisol concentrations (Sutherland et al., 2012) in temperamental cattle compared with calmer ones. In these studies, higher basal cortisol levels may reflect that behaviorally more reactive animals can anticipate the experience of human handling before blood sampling. The overall HPA response, peak cortisol levels, and amplitude of the plasma and salivary cortisol response were greater in high responder cows, which possibly indicates that low responder animals were not as excited by the manipulation as high responders.

Two studies have reported on the HPA responsiveness of temperamental and calm cattle giving contradictory results. Opposed to the present observation, Curley et al. (2008) found that behaviorally more reactive Brahman beef heifers (assessed using an exit speed test) had a lower cortisol response than calm ones following ACTH administration, whereas Sutherland et al. (2012) observed no difference in HPA axis output between temperament groups in response to the $\mathrm{ACTH}$ challenge. In these studies, the muted responsiveness of behaviorally more reactive animals was possibly a consequence of serial blood sampling before the challenge.

In accordance with HPA measures, cardiac autonomic activity was altered during and following the examination in both groups, measured in either time or

Table 4. Mean \pm SD frequency of vocalization and attendant behavior (turning head backward) during the baseline period, the transrectal examination, and during the first 5 min postexamination for low responder (n $=20)$ and high responder $(\mathrm{n}=20)$ cows

\begin{tabular}{llcc}
\hline Temperament group & & $\begin{array}{c}\text { Vocalization } \\
(1 / \mathrm{min})\end{array}$ & $\begin{array}{c}\text { Attendance } \\
(1 / \mathrm{min})\end{array}$ \\
\hline Low responder & Baseline $^{1}$ & $-^{2}$ & $0.6 \pm 0.5$ \\
& Examination & $2.3 \pm 0.9$ & $3.1 \pm 1.1$ \\
High responder & Postexamination & - & - \\
& Baseline & $2.7 \pm 1.2$ & $3.3 \pm 0.5$ \\
& Examination & & - \\
\hline
\end{tabular}

${ }^{1}$ The last 5 min before the first blood and saliva sampling before examination.

${ }^{2}$ No occurrences of behavior $(0.0 \pm 0.0)$. 
frequency domains, supporting that HRV could be influenced by acute pain (von Borell et al., 2007). Reports on calves during ear tagging (Stewart et al., 2013) and surgical castration (Stewart et al., 2010) have shown similar results demonstrating that pain-evoking events clearly affect HRV. Heart rate and LF/HF ratio significantly increased, reaching their maximal values during the examination, which suggests a stronger domination of the SNS. The animals showed no physical activity during the experiment, which might have influenced the results.

The RMSSD and HF showed a sudden decrease in both low responder and high responder cows, indicative for an increase in baroreflex activity and a decrease in vagal tone. These findings support the poly-vagal theory of Porges (2003), namely that painful stimuli are causing a decrease in PNS activity. In human studies, pain-related decrease in vagal tone was indicated by frequency-domain measures of HRV (Koenig et al., 2014). In the present study, the decline in PNS activity in parallel with increased HR for both groups confirms that rapid changes in HR are associated with changes in the vagal regulatory activity (Eckberg, 1991). Similarly to a previous finding in lactating and nonlactating cows (Kovács et al., 2014b), a compensatory peak occurred right after the examination, which might be related to relaxation of the animals after the procedure or activation of the PNS due to the manipulation of the hind gut. Ten minutes after the examination, PNS measures decreased below baseline and slowly returned between min 20 and 120 following the examination [Figures 2(b) and $2(\mathrm{c})]$. During the gradual increase in vagal tone, a parallel decrease in plasma and saliva cortisol in both groups suggests that the PNS might be involved in the recovery of the HPA response (Arnhold et al., 2009). Although the greatest changes in all cardiac measures were observed at the time of the procedure with minimal (RMSSD and HF) or maximal values (HR and LF/ $\mathrm{HF}$ ), peaks of plasma and saliva cortisol concentrations occurred 20 and $30 \mathrm{~min}$ after the procedure, based on reactivity. The present findings are in accordance with earlier findings on HR and HRV being more immediate indicators of stress than HPA measures (Mialon et al., 2012) and that changes in ANS activity occur rapidly in response to acute pain (Ledowski et al., 2012). Earlier studies on calves suggest that the slow response of cortisol levels is an insensitive measure of acute pain during the first few minutes of noxious stimuli (Stewart et al., 2008).

Baseline HR was higher in high responder cows compared with low responders in accordance with an earlier observation of higher HR in cows characterized by active response to interaction with humans compared with calm animals during lying (Kovács et al., 2015b), and Sutherland et al. (2012) also found evidence for basal HR differences between temperament groups in a standing posture. Heart rate AUC parameters gave contradictory results. Despite the higher basal HR of high responder cows, area under HR response curve was surprisingly greater in low responders than in high responders (Table 4); however, the difference between maximal HR and the amplitudes of the HR responses was not significant. Though these findings might indicate higher cardiac responsiveness in low responder animals, it has to be considered that baseline HR differences were significant and that cardiac autonomic reactivity cannot be estimated based solely on the HR response (von Borell et al., 2007).

Basal ANS activity was very similar in both temperament groups as indicated by PNS and SNS HRV parameters, suggesting that the presence of experimenters during the last 5 min before the transrectal examination (baseline period for behavioral observations) did not cause greater stress for high responder cows than for low responders. Although, in an earlier study, considerably higher basal SNS and lower PNS tone were observed in behaviorally more reactive cows compared with relatively calmer animals in lying posture (Kovács et al., 2015b), in the present work, physical activity related to standing position might mask the differences caused by behavioral reactivity. Earlier papers reported similar HRV values in cows standing under unrestrained conditions without human presence (Hagen et al., 2005; Kovács et al., 2015a), which seems to confirm that cows in the present study were already habituated to human interaction in the time of the day when the examinations took place.

The differences in SNS reactivity deriving for different behavioral reactivity were similar to those found in relation with HPA responsiveness. As expected, all investigated $\mathrm{LF} / \mathrm{HF}$ response parameters were higher in high responder cows compared with low responders following the examination, suggesting a shift of the sympathovagal balance toward a sympathetic dominance in behaviorally more reactive cows. In line with the present results, Frondelius et al. (2015) found higher sympathetic tone during a handling test; however, authors did not assess the long-term activation of the SNS. In the present study, both short- (maximum, amplitude) and long-term responses (area under the $\mathrm{LF} / \mathrm{HF}$ response curve) were greater in high responder cows compared with low responders, suggesting that the early response of the ANS manifests in prolonged SNS activation in high responder animals. This prolonged activation of the SNS might be indicative of higher coping capacity of behaviorally more reactive animals (Reale et al., 2007). The PNS indices showed differences in ANS reactivity between groups only in 
the short term. Though the minimum values of PNS indices calculated for the time of transrectal examination showed clear differences in vagal reactivity between high and low responder animals, the differences between RMSSD and HF responses could not be distinguished, as areas under the response curves were similar.

Earlier works suggest that cortisol concentration is not a direct measure of pain, but rather the indicator of the overall noxiousness of the experience (Mellor et al., 2000); however, in the present study, behavioral reactions indicate a possible connection between pain and neuroendocrine responses. Although the nature of the transrectal examination prevented various pain-related behaviors from being observed, the frequency of the 2 studied behaviors was high during the time of the examination in both groups. As opposed to HPA and cardiac autonomic responses, no differences were found in behavioral responses to the examination between groups. This finding supports earlier suggestions that in cattle, spontaneous behaviors such as head turning (Marti et al., 2010) or vocalization (Grandin, 2001) provide a good indication of the existence and duration of pain, but may not indicate the maximal intensity of a noxious experience as well as physiological indicators, such as corticosteroid concentrations (Mellor et al., 2000). Another explanation for the similarity of behavioral reactions of groups could be that animals are more likely to hide pain-related behaviors when they see people watching (Stafford and Mellor, 2010). It is possible, that this cover-up phenomenon eliminated the possible differences between low responder and high responder animals in the present study. The absence of behavioral differences between groups highlights the importance of both salivary and plasma cortisol determination in studying bovine stress sensitivity.

Besides their scientific relevance, the present results have important implications for dairy cattle practice as well. As stress caused by transrectal examination was reflected by ANS and HPA measures in both behaviorally more and less reactive animals, the frequency of the transrectal examination should be as minimal as possible. Considering that in the case of routine checkups and treatments (pregnancy diagnosis, artificial insemination, involution, estrus detection), a skilled person performs a transrectal examination in a matter of almost seconds, the frequency and duration of such examinations is particularly important in practical training (veterinary or other, husbandry-related courses).

\section{CONCLUSIONS}

In summary, transrectal examination of dairy cows leads to increased plasma and salivary cortisol con- centrations and changes in HR, HRV, and behavior that are indicative of pain. Cardiac responses occurred earlier than HPA responses. Plasma and salivary cortisol concentrations were greater and sympathetic responsiveness was higher in behaviorally more reactive cows than in relatively calmer ones. Frequencies of behavioral reactions were similar across temperament groups. These findings indicate that salivary cortisol could substitute for plasma cortisol when assessing response of cattle to severe stress. Cortisol concentrations and the assessment of cardiac autonomic function complement each other, providing a reliable alternative for the assessment of acute pain in dairy cattle. Behavioral reactivity and the duration of transrectal examination have to be taken into consideration when unskilled persons (e.g., students in training) perform the procedure.

\section{ACKNOWLEDGMENTS}

The authors thank the farm staff of Bóly Co. at Beremend, Csípőtelek, Hungary, for taking care of the animals and for their help in during the examinations. The authors are indebted to Mikolt Bakony for correcting the English. Levente Kovács was supported by the Research Centre of Excellence-9878-3/2016/FEKUT project (Budapest, Hungary).

\section{REFERENCES}

Akselrod, S., D. Gordon, F. A. Ubel, D. C. Shannon, A. C. Berger, and R. J. Cohen. 1981. Power spectrum analysis of heart rate fluctuation: A quantitative probe of beat-to-beat cardiovascular control. Science 213:220-222.

Arnhold, M. M., J. M. Yoder, and W. C. Engeland. 2009. Subdiaphragmatic vagotomy prevents drinking-induced reduction in plasma corticosterone in water-restricted rats. Endocrinology 150:2300-2307.

Benarroch, E. E. 2006. Pain-autonomic interactions. Neurol. Sci. 27:S130-S133.

Blackshaw, J. K., and A. W. Blackshaw. 1989. Limitations of salivary and blood cortisol determinations in pigs. Vet. Res. Commun. 13:265-271.

Bohák, Zs., J.-F. Beckers, N. Melo de Sousa, O. Kutasi, K. Nagy, and O. Szenci. 2013. Monitoring the circadian rhythm of serum and salivary cortisol concentrations in the horse. Domest. Anim. Endocrinol. 45:38-42.

Cingi, C. C., D. F. Baser, Y. S. Karafakioglu, and A. F. Fidan. 2012. Stress response in dairy cows related to rectal examination. Acta Sci. Vet. 40:1053.

Cook, N. J. 2012. Review: Minimally invasive sampling media and the measurement of corticosteroids as biomarkers of stress in animals. Can. J. Anim. Sci. 92:227-259.

Cook, N. J., A. L. Schaefer, P. Lepage, and S. Morgan Jones. 1996. Salivary vs. serum cortisol for the assessment of adrenal activity in swine. Can. J. Anim. Sci. 76:329-335.

Csernus, V. 1982. Antibodies of high affinity and specificity for RIA determination of progesterone, testosterone, estradiol-173 and cortisol. Pages 171-177 in Advances in Steroid Analysis. S. Görög, ed. I. Acad. Press, Budapest, Hungary.

Curley, K. O. Jr., D. A. Neuendorff, A. W. Lewis, J. J. Cleere, T. H. Welsh, and R. D. Randel. 2008. Functional characteristics of the 
bovine hypothalamic-pituitary-adrenal axis vary with temperament. Horm. Behav. 53:20-27.

Curley, K. O. Jr., J. C. Paschal, T. H. Welsh Jr., and R. D. Randel. 2006. Technical note: Exit velocity as a measure of cattle temperament is repeatable and associated with serum concentration of cortisol in Brahman bulls. J. Anim. Sci. 84:3100-3103.

De Passillé, A. M., J. Rushen, and F. Martin. 1995. Interpreting the behaviour of calves in an open field test: A factor analysis. Appl. Anim. Behav. Sci. 45:201-213.

Eckberg, D. L. 1991. Human respiratory-cardiovascular interactions in health and disease. Pages 253-258 in Cardiorespiratory and Motor Coordination. H. P. Koepchen, and T. Huopaniemi, ed. Springer Verlag, Berlin, Heidelberg, Germany.

ESC-NASPE Task Force (Task Force of the European Society of Cardiology, North American Society of Pacing and Electrophysiology). 1996. Heart rate variability: Standards of measurement, physiological interpretation, and clinical use. Circulation 93:1043-1065.

Fekedulegn, D. B., M. E. Andrew, C. M. Burchfiel, J. M. Violanti, T. A. Hartley, L. E. Charles, and D. B. Miller. 2007. Area under the curve and other summary indicators of repeated waking cortisol measurements. Psychosom. Med. 69:651-659.

Fell, L. R., I. G. Colditz, K. H. Walker, and D. L. Watson. 1999. Associations between temperament, performance and immune function in cattle entering a commercial feedlot. Aust. J. Exp. Agric. 39:795-802.

Fell, L. R., D. A. Shutt, and C. J. Bentley. 1985. Development of a salivary cortisol method for detecting changes in plasma "free" cortisol arising from acute stress in sheep. Aust. Vet. J. 62:403-406.

Fenzl, T., C. Touma, C. P. N. Romanowski, J. Ruschel, F. Holsboer, R. Landgraf, M. Kimura, and A. Yassouridis. 2011. Sleep disturbances in highly stress reactive mice: Modeling endophenotypes of major depression. BMC Neurosci. 12:29 http://dx.doi. org/10.1186/1471-2202-12-29.

Fidan, A. F., K. Pamuk, A. Ozdemir, Z. K. Saritas, and U. Tarakci 2010. Effects of dehorning by amputation on oxidant-antioxidant status in mature cattle. Rev. Med. Vet. 161:502-508.

Fokkema, D., K. Smit, J. Van der Gugten, and J. M. Koolhaas. 1988. A coherent pattern among social behavior, blood pressure, corticosterone, and catecholamines measures in individual male rats. Physiol. Behav. 42:485-489.

Forkman, B., A. Boissy, M. C. Meunier-Salaün, E. Canali, and R. B. Jones. 2007. A critical review of fear tests used on cattle, pigs, sheep, poultry and horses. Physiol. Behav. 92:340-374.

Frondelius, L., K. Järvenranta, T. Koponen, and J. Mononen. 2015. The effects of body posture and temperament on heart rate variability in dairy cows. Physiol. Behav. 139:437-441.

Grandin, T. 2001. Cattle vocalizations are associated with handling and equipment problems at beef slaughter plants. Appl. Anim. Behav. Sci. 71:191-201.

Gygax, L., I. Neuffer, C. Kaufmann, R. Hauser, and B. Wechsler. 2008. Restlessness behaviour, heart rate and heart-rate variability of dairy cows milked in two types of automatic milking systems and auto-tandem milking parlours. Appl. Anim. Behav. Sci. 109:167-179.

Haga, H. A., and B. Ranheim. 2005. Castration of piglets: The analgesic effects of intratesticular and intrafunicular lidocaine injection. Vet. Anaesth. Analg. 32:1-9.

Hagen, K., J. Langbein, C. Schmied, D. Lexer, and S. Waiblinger. 2005. Heart rate variability in dairy cows - Influences of breed and milking system. Physiol. Behav. 85:195-204.

Hellhammer, D. H., S. Wüst, and B. M. Kudielka. 2009. Salivary cortisol as a biomarker in stress research. Psychoneuroendocrinology 34:163-171.

Hernandez, C. E., T. Thierfelder, K. Svennersten-Sjaunja, C. Berg, A. Orihuela, and L. Lidfors. 2014. Time lag between peak concentrations of plasma and salivary cortisol following a stressful procedure in dairy cattle. Acta Vet. Scand. 56:61.

Kirschbaum, C. 2000. Salivary cortisol. Pages 379-383 in Encyclopedia of Stress. G. Fink, ed. Academic Press, San Diego, CA.

Koenig, J., M. N. Jarczok, R. J. Ellis, T. K. Hillecke, and J. F. Thayer. 2014. Heart rate variability and experimentally induced pain in healthy adults: A systematic review. Eur. J. Pain http://dx.doi. org/10.1002/j.1532-2149.2013.00379.x.

Koolhaas, J. M., S. F. de Boer, C. M. Coppens, and B. Buwalda. 2010. Neuroendocrinology of coping styles: Towards understanding the biology of individual variation. Front. Neuroendocrinol. 31:307-321.

Kovács, L., M. Bakony, J. Tözsér, and V. Jurkovich. 2013. Short communication: The effect of milking in a parallel milking parlor with non-voluntary exit on the HRV of dairy cows. J. Dairy Sci. 96:7743-7747.

Kovács, L., V. Jurkovich, M. Bakony, P. Póti, O. Szenci, and J. Tőzsér. 2014a. Welfare assessment in dairy cattle by heart rate and heart rate variability - Literature review and implications for future research. Animal 8:316-330.

Kovács, L., F. L. Kézér, M. Bakony, L. Hufnágel, J. Tőzsér, and V. Jurkovich. 2015a. Associations between heart rate variability parameters and housing- and individual-related variables in dairy cows using canonical correspondence analysis. PLoS ONE 10:e145313. http://dx.doi.org/10.1371/journal.pone.0145313.

Kovács, L., F. L. Kézér, F. Ruff, and O. Szenci. 2016. Cardiac autonomic activity has a circadian rhythm in summer but not in winter in non-lactating pregnant dairy cows. Physiol. Behav. 155:56-65.

Kovács, L., F. L. Kézér, J. Tőzsér, O. Szenci, P. Póti, and F. Pajor. 2015b. Heart rate and heart rate variability in dairy cows with different temperament and behavioural reactivity to humans. PLoS ONE 10:e0136294. http://dx.doi.org/10.1371/journal pone.0136294.

Kovács, L., J. Tőzsér, F. L. Kézér, F. Ruff, M. Aubin-Wodala, E. Albert, A. Choukeir, Z. Szelényi, and O. Szenci. 2015c. Heart rate and heart rate variability in multiparous dairy cows with unassisted calvings in the periparturient period. Physiol. Behav. 139:281-289.

Kovács, L., J. Tőzsér, O. Szenci, P. Póti, F. L. Kézér, F. Ruff, Gy. Gábriel-Tőzsér, D. Hoffmann, M. Bakony, and V. Jurkovich. 2014b. Cardiac responses to palpation per rectum in lactating and nonlactating dairy cows. J. Dairy Sci. 97:6955-6963.

Kudielka, B. M., D. H. Hellhammer, and S. Wüst. 2009. Why do we respond so differently? (Reviewing determinants of human salivary cortisol responses to challenge). Psychoneuroendocrinology 34:2-18.

Lay, D. C. Jr., T. H. Friend, R. D. Randel, C. L. Bowers, K. K. Grissom, and O. C. Jenkins. 1992. Behavioral and physiological effects of freeze or hot-iron branding on crossbred cattle. J. Anim. Sci. 70:330-336.

Lay, D. C. Jr., T. H. Friend, R. D. Randel, O. C. Jenkins, D. A. Neuendorff, G. M. Kapp, and D. M. Bushong. 1996. Adrenocorticotropic hormone dose response and some physiological effects of transportation on pregnant Brahman cattle. J. Anim. Sci. 74:1806-1811.

LeBlanc, S. J., T. F. Duffield, K. E. Leslie, K. G. Bateman, G. P Keefe, J. S. Walton, and W. H. Johnson. 2002. Defining and diagnosing postpartum clinical endometritis and its impact on reproductive performance in dairy cows. J. Dairy Sci. 85:2223-2236.

Ledowski, T., M. Reimer, V. Chavez, V. Kapoor, and M. Wenk. 2012. Effects of acute postoperative pain on catecholamine plasma levels, hemodynamic parameters, and cardiac autonomic control. Pain 153:759-764.

Lefcourt, A. M., J. Bitman, S. Kahl, and D. L. Wood. 1993. Circadian and ultradian rhythms of peripheral cortisol concentrations in lactating dairy cows. J. Dairy Sci. 76:2607-2612.

Livingston, A. 2010. Pain and analgesia in domestic animals. Handb. Exp. Pharmacol. 199:159-189.

Marchant-Forde, R. M., D. J. Marlin, and J. N. Marchant-Forde. 2004. Validation of a cardiac monitor for measuring heart rate variability in adult female pigs: Accuracy, artefacts and editing. Physiol. Behav. 80:449-458

Marti, S., A. Velarde, J. L. De La Torre, A. Bach, A. Aris, A. Serrano, X. Manteca, and M. Devant. 2010. Effects of ring castration with local anesthesia and analgesia in Holstein calves at 3 months of age on welfare indicators. J. Anim. Sci. 88:2789-2796.

Mellor, D. J., C. J. Cook, and K. J. Stafford. 2000. Quantifying some responses to pain as a stressor. Pages $171-198$ in The Biology 
of Animal Stress: Basic Principles and Implications for Animal Welfare. G. P. Moberg and J. A. Mench, ed. CABI Publishing, Wallingford, UK.

Mialon, M. M., V. Deiss, S. Andanson, F. Anglard, M. Doreau, and I. Veissier. 2012. An assessment of the impact of rumenocentesis on pain and stress in cattle and the effect of local anaesthesia. Vet. J. 194:55-59.

Mohr, E., J. Langbein, and G. Nürnberg. 2002. Heart rate variability: A noninvasive approach to measure stress in calves and cows. Physiol. Behav. 75:251-259.

Molony, V., and J. E. Kent. 1997. Assessment of acute pain in farm animals using behavioral and physiological measurements. J. Anim. Sci. 75:266-272.

Mormède, P., S. Andanson, B. Aupérin, B. Beerda, D. Guémené, J. Malmkvist, X. Manteca, G. Manteuffel, P. Prunet, C. G. van Reenen, S. Richard, and I. Veissier. 2007. Exploration of the hypothalamic-pituitary-adrenal function as a tool to evaluate animal welfare. Physiol. Behav. 92:317-339.

Möstl, E., and R. Palme. 2002. Hormones as indicators of stress. Domest. Anim. Endocrinol. 23:67-74.

Nakao, T., T. Sato, M. Moriyoshi, and K. Kawata. 1994. Plasma cortisol response in dairy cows to vaginoscopy, genital palpation per rectum and artificial insemination. J. Vet. Med. 41:16-21.

Negrao, J. A., M. A. Porcionato, A. M. de Passille, and J. Rushen. 2004. Cortisol in saliva and plasma of cattle after ACTH administration and milking. J. Dairy Sci. 87:1713-1718.

Pilz, M., C. Fischer-Tenhagen, G. Thiele, H. Tinge, F. Lotz, and W. Heuwieser. 2012. Behavioural reactions before and during vaginal examination in dairy cows. Appl. Anim. Behav. Sci. 138:18-27.

Porges, S. W. 2003. The polyvagal theory: Phylogenetic contributions to social behavior. Physiol. Behav. 79:503-513.

Prunier, A., L. Mounier, P. Le Neindre, C. Leterrier, P. Mormède, V. Paulmier, P. Prunet, C. Terlouw, and R. Guatteo. 2013. Identifying and monitoring pain in farm animals: A review. Animal 7:998-1010.

R Core Team. 2013. R: A language and environment for statistical computing. R Foundation for Statistical Computing, Vienna, Austria. http://www.R-project.org/.

Rahman, F., S. Pechnik, D. Gross, L. Sewell, and D. S. Goldstein. 2011. Low frequency power of heart rate variability reflects baroreflex function, not cardiac sympathetic innervation. Clin. Auton. Res. 21:133-141

Reale, D., S. M. Reader, D. Sol, P. T. McDougall, and N. J. Dingemanse. 2007. Integrating animal temperament within ecology and evolution. Biol. Rev. Camb. Philos. Soc. 82:291-318.

Rietmann, T. R., M. Stauffacher, P. Bernasconi, J. A. Auer, and M. A. Weishaupt. 2004. The association between heart rate, heart rate variability, endocrine and behavioural pain measures in horses suffering from laminitis. J. Vet. Med. A 51:218-225.

Romano, J. E., J. A. Thompson, D. C. Kraemer, M. E. Westhusin, D. W. Forrest, and M. A. Tomaszweski. 2007. Early pregnancy diagnosis by palpation per rectum: Influence on embryo/fetal viability in dairy cattle. Theriogenology 67:486-493.

Rushen, J., L. Munksgaard, P. G. Marnet, and A. M. De Passillé. 2001. Human contact and the effects of acute stress on cows at milking. Appl. Anim. Behav. Sci. 73:1-14.

Sgoifo, A., S. F. De Boer, J. Haller, and J. M. Koolhaas. 1996. Individual differences in plasma catecholamine and corticosterone stress responses of wildtype rats: Relationship with aggression. Physiol. Behav. 60:1403-1407.

Stafford, K. J., and D. J. Mellor. 2010. Painful husbandry procedures in livestock and poultry. Pages 88-114 in Improving Animal Wel- fare: A Practical Approach. T. Grandin, ed. CABI Publishing, Wallingford, UK.

Stafford, K. J., and D. J. Mellor. 2011. Addressing the pain associated with disbudding and dehorning in cattle. Appl. Anim. Behav. Sci. 135:226-231.

Stewart, M., H. M. Shepherd, J. R. Webster, J. R. Waas, L. M. McLeay, and K. E. Schütz. 2013. Effect of previous handling experiences on responses of dairy calves to routine husbandry procedures. Animal 7:828-833.

Stewart, M., K. J. Stafford, S. K. Dowling, A. L. Schaefer, and J. R. Webster. 2008. Eye temperature and heart rate variability of calves disbudded with or without local anaesthetic. Physiol. Behav. 93:789-797.

Stewart, M., G. A. Verkerk, K. J. Stafford, A. L. Schaefer, and J. R. Webster. 2010. Noninvasive assessment of autonomic activity for evaluation of pain in calves, using surgical castration as a model. J. Dairy Sci. 93:3602-3609.

Stubsjøen, S. M., A. S. Flø, R. O. Moe, A. M. Janczak, E. Skjerve, P. S. Valle, and A. J. Zanella. 2009. Exploring non-invasive methods to assess pain in sheep. Physiol. Behav. 98:640-648.

Sutherland, M. A., A. R. Rogers, and G. A. Verkerk. 2012. The effect of temperament and responsiveness towards humans on the behavior, physiology and milk production of multi-parous dairy cows in a familiar and novel milking environment. Physiol. Behav. 107:329-337.

Tarvainen, M. P., J.-P. Niskanen, J. A. Lipponen, P. O. Ranta-aho, and P. A. Karjalainen. 2014. Kubios HRV-Heart rate variability analysis software. Comput. Methods Programs Biomed. 113:210220

Thayer, J. F., F. Ahs, M. Fredrikson 3rd, J. J. Sollers, and T. D. Wager. 2012. A meta-analysis of heart rate variability and neuroimaging studies: Implications for heart rate variability as a marker of stress and health. Neurosci. Biobehav. Rev. 36:747-756.

Unshelm, J. 1990. Introductory comments. In The Role of The Stockman in Livestock Productivity and Management. M. F. Seabrook, ed. Report EUR 10982 EN.

van Ravenswaaij-Arts, C. M., L. A. Kollée, J. C. Hopman, G. B. Stoelinga, and H. P. van Geijn. 1993. Heart-rate-variability. Ann. Intern. Med. 118:436-447.

Veissier, I., C. G. van Reenen, S. Andanson, and I. E. Leushuis. 1999. Adrenocorticotropic hormone and cortisol in calves after corticotropin-releasing hormone. J. Anim. Sci. 77:2047-2053.

Vincent, I. C., and A. R. Michell. 1992. Comparison of cortisol concentrations in saliva and plasma of dogs. Res. Vet. Sci. 53:342-345.

Visser, E. K., C. G. van Reenen, J. T. N. van der Werf, M. B. H. Schilder, J. H. Knaap, A. Barneveld, and H. J. Blokhuis. 2002. Heart rate and heart rate variability during a novel object test and a handling test in young horses. Physiol. Behav. 76:289-296.

von Borell, E., J. Langbein, G. Després, S. Hansen, C. Leterrier, J. Marchant-Forde, R. Marchant-Forde, M. Minero, E. Mohr, A. Prunier, D. Valance, and I. Veissier. 2007. Heart rate variability as a measure of autonomic regulation of cardiac activity for assessing stress and welfare in farm animals: A review. Physiol. Behav. 92:293-316.

Waiblinger, S., C. Menke, J. Korf, and A. Bucher. 2004. Previous handling and gentle interactions affect behaviour and heart rate of dairy cows during a veterinary procedure. Appl. Anim. Behav. Sci. 85:31-42.

Wenzel, C., S. Schonreiter-Fischer, and J. Unshelm. 2003. Studies on step-kick behavior and stress of cows during milking in an automatic milking system. Livest. Prod. Sci. 83:237-246. 